CHRONIC OBSTRUCTIVE PULMONARY DISEASE

\title{
Prevalence, diagnosis and relation to tobacco dependence of chronic obstructive pulmonary disease in a nationally representative population sample
}

\author{
L Shahab, M J Jarvis, J Britton, R West
}

Thorax 2006;61:1043-1047. doi: 10.1136/thx.2006.064410

See end of article for authors' affiliations

Correspondence to: L Shahab, MSc, Cancer Research Health Behaviour Unit, Department of Epidemiology and Public Health, University College London, London WCIE 6BT, UK; lion.shahab@ucl. ac.uk

Received 27 April 2006 Accepted 25 August 2006

\begin{abstract}
Background: Chronic obstructive pulmonary disease (COPD) is the fourth most common cause of death worldwide. It is caused primarily by cigarette smoking. Given its importance, it is remarkable that reliable national prevalence data are lacking for most countries. This study provides estimates of the national prevalence of COPD in England, the extent of under-detection of the disorder, and patterns of cigarette smoking, dependence, and motivation to stop smoking in those with the disease.

Methods: Data from 8215 adults over the age of 35 who participated in the Health Survey for England were analysed. Information was obtained on self-reported and cotinine validated smoking status, cigarette dependence, motivation to stop smoking, COPD defined by spirometry using joint American Thoracic Society and European Respiratory Society criteria, and self-reports of diagnosis with respiratory disorders. Results: Spirometry-defined COPD was present in $13.3 \%(95 \% \mathrm{Cl} 12.6$ to 14.0 ) of participants, over $80 \%$ of whom reported no respiratory diagnosis. Even among people with severe or very severe COPD by spirometric assessment, only $46.8 \%(95 \% \mathrm{Cl} 39.1$ to 54.6$)$ reported any diagnosed respiratory disease. A total of $34.9 \%(95 \% \mathrm{Cl} 32.1$ to 37.8$)$ of people with spirometry-defined COPD were smokers compared with $22.4 \%$ (95\% Cl 21.4 to 23.4 ) of those without, and smoking prevalence increased with disease severity. Smokers with spirometry-defined COPD were more cigarette dependent but had no greater desire to quit than other smokers.

Conclusion: COPD is common among adults in England and is predominantly undiagnosed. In smokers it is associated with higher degrees of cigarette dependence but not with a greater motivation to stop smoking.
\end{abstract}

Abbreviations: COPD, chronic obstructive pulmonary disease; $\mathrm{FEV}_{1}$, forced expiratory volume in 1 second; FVC, forced vital capacity; PEF, peak expiratory flow

included objective measures of both lung function and tobacco smoking, to describe the prevalence and extent of underdetection of spirometry-defined COPD in England, and the smoking patterns, nicotine dependence, and motivation to stop smoking in smokers with COPD in the general population.

\section{METHODS}

\section{Participants}

The HSE is an annual cross-sectional household survey that assesses the health of the population of England using a two stage process: an individual home interview, followed by a visit from a nurse who carries out a number of objective health assessments. The HSE in 2001 focused on asthma, respiratory conditions and disability, and included an assessment of lung function as well as collection of saliva samples for cotinine assay. The methodology has been described in detail elsewhere. ${ }^{23}$ Briefly, private households are identified with a multi-stage probability sampling design and its members invited to participate. Of eligible households, $74 \%(n=9373)$ agreed to take part in the 2001 survey. In cooperating households, 15647 adults (89\% response rate) were interviewed and 12404 adults (71\% response rate) saw a nurse who obtained lung function measures from 11611 and valid cotinine saliva samples from 9451 participants.

\section{Measurements}

Demographic data

During the interview data were collected on age, sex, ethnicity, and occupational status (by head of household). moderate COPD can be helped to stop and that this has a beneficial effect on lung function and mortality. ${ }^{21} 22$

We now report a study using data from the Health Survey for England (HSE), a nationally representative survey which has peak expiratory flow 
A deprivation score was computed from five measures (car ownership, educational attainment, housing tenure, employment status, and occupation). Participants scored one for each of: no car; no qualifications; living in rented accommodation; being unemployed; and manual occupation. This gave a maximum deprivation score of five. ${ }^{24}$

\section{Lung function}

Lung function was assessed by a trained nurse using a spirometer (Vitalograph Escort, Buckingham, UK) to measure forced expiratory volume in 1 second $\left(\mathrm{FEV}_{1}\right)$, forced vital capacity (FVC), and peak expiratory flow (PEF). A total of five attempts were made and indicators of lung function obtained from the blow judged to be technically most satisfactory according to HSE guidelines were used in the analysis.

\section{Saliva cotinine}

Saliva samples were collected using a dental roll which participants were asked to keep in the mouth until saturated. Samples were assayed for cotinine using a well established rapid gas liquid chromatography technique. ${ }^{25}$ Cotinine is a major metabolite of nicotine that provides an extremely sensitive and specific quantitative measurement of smoking. In the absence of the use of nicotine replacement products, saliva cotinine concentrations above $15 \mathrm{ng} / \mathrm{ml}$ usually indicate current smoking. ${ }^{26}$ However, as spit tobacco consumption was not assessed in this sample and to account for unreported use of nicotine replacement therapy, the cut-off level was increased to $30 \mathrm{ng} / \mathrm{ml}$ for the analysis.

\section{Respiratory disease}

Objective assessment

Measures from the lung function test were used to determine COPD according to joint American Thoracic Society (ATS) and European Respiratory Society (ERS) guidelines. ${ }^{27}$ COPD is defined as an $\mathrm{FEV}_{1} / \mathrm{FVC}$ ratio below 0.7 . In the presence of this obstruction, $\mathrm{FEV}_{1}$ above $80 \%$ of the predicted value is categorised as mild, $\mathrm{FEV}_{1}$ between $50 \%$ and $79 \%$ of the predicted value as moderate, $\mathrm{FEV}_{1}$ between $30 \%$ and $49 \%$ of the predicted value as severe, and $\mathrm{FEV}_{1}$ below $30 \%$ of the predicted value as very severe COPD. Since numbers in these latter two groups were small, they were combined for the purposes of this analysis. Predicted values are based on age, sex and height adjusted expected population reference norms for lung function measurements. ${ }^{28}$

\section{Self-report}

During the interview, respondents were asked if they had any longstanding illness or disability. If they responded yes, they were asked what the condition was and up to six different infirmities were recorded. Respiratory diseases were coded as "chronic bronchitis and/or emphysema", "asthma", or "other respiratory complaints". If participants volunteered that they had any of these conditions, they were considered to have been diagnosed. We defined COPD as "undiagnosed" if participants with spirometry-defined COPD did not report having any of the above conditions.

\section{Smoking status}

Cigarette smoking status was assessed by self-report and saliva cotinine analysis.

Participants classified themselves as current cigarette smokers, ex-smokers, or non-smokers. They also reported how long they had been smoking for and, if applicable, how long ago they had stopped smoking. Cotinine concentrations above $30 \mathrm{ng} / \mathrm{ml}$ in self-reported ex-smokers or non-smokers who did not indicate use of nicotine replacement therapy were taken to imply current smoking.

\section{Smoking characteristics}

Cigarette dependence was estimated by the Heaviness of Smoking Index (HSI), ${ }^{29}$ a short version of the Fagerström test for nicotine dependence. The HSI is calculated from the time to the first cigarette (4 categories, $0-3$ ) and cigarettes per day ( 4 categories, $0-3$ ) producing a scale from 0 to 6 with higher scores indicating greater nicotine dependence. Motivation to stop smoking was assessed by a single questionnaire item that asked smokers whether they would like to give up smoking altogether (yes/no).

\section{Statistical analysis}

Data were not weighted in adults as comparison with the 2001 census indicated that the sample was sufficiently representative of the population..$^{23}$ Since COPD is a disease which is rarely diagnosed in young adults, ${ }^{30}$ we restricted all our analyses to people above 35 years of age. Data were analysed using SPSS 13.0. Group differences for and adjustments of continuous variables were analysed by univariate ANOVA followed by Tukey HSD post-hoc test to determine which group differences, if any, were reliable. $\chi^{2}$ tests were carried out to investigate between group differences for categorical and dichotomous variables; adjustments in proportions were compared using the Mantel-Haenszel test and calculated by the direct standardisation method using the total study population as the standard. Where appropriate, partial correlation and logistic regression analyses were conducted to evaluate associations between variables and to estimate odds ratios. Significance values were adjusted to account for multiple comparisons using Bonferroni correction.

\section{RESULTS}

\section{Prevalence and diagnosis of COPD}

From a total of 15647 respondents, 11101 were aged over 35 years and, of those, 8215 had valid spirometric data. Demographic and smoking characteristics of this sample are provided in table 1 . Those excluded because of missing spirometric data did not differ on any smoking characteristic; however, they were more likely to be manual workers, older, female and deprived. Spirometry-defined COPD was present in 1093 individuals $(13.3 \%, 95 \%$ CI 12.6 to 14.0 of respondents, table 2). Moderate COPD was found in $5.8 \%$, mild in $5.5 \%$, and severe or very severe COPD in $1.9 \%$. COPD was most common among current smokers (19.3\%) followed by ex-smokers $(15.2 \%)$ and never smokers $(8.2 \%)$. These differences were significant between all groups and the gap in COPD prevalence between current or ex-smokers and never smokers increased in relation to disease severity (table 2). Although the absolute number of COPD cases was nearly equal for never and former or current smokers, this was primarily due to the larger number of mild cases among never smokers.

Figure 1 shows an approximately linear increase in the prevalence of COPD with age, irrespective of smoking status. However, this increase was steeper among current and exsmokers so that almost half of smokers above 65 years of age had some lung function impairment compared with only 15\% of never smokers. In addition, moderate and severe or very severe COPD was more prevalent and also occurred earlier in current and former smokers, while even in the oldest age group only a very small proportion of never smokers developed the most acute form of COPD.

Only $18.8 \%$ (95\% CI 16.4 to 21.1 ) of those with spirometrydefined COPD reported having been diagnosed with a respiratory disease of any kind (table 1). Thus, in adults above 35 years of age, there were more than four undiagnosed cases of spirometry-defined COPD for every case reporting any respiratory disease. The extent of this 
Table 1 Characteristics of patients according to spirometry-defined COPD grade

\begin{tabular}{|c|c|c|c|c|c|c|}
\hline & \multirow[b]{2}{*}{$\begin{array}{l}\text { Total sample } \\
(\mathrm{N}=8215)\end{array}$} & \multirow[b]{2}{*}{$\begin{array}{l}\text { No COPD } \\
(\mathrm{N}=7122)\end{array}$} & \multirow[b]{2}{*}{$\begin{array}{l}\text { COPD } \\
(\mathrm{N}=1093)\end{array}$} & \multicolumn{3}{|l|}{ COPD grade } \\
\hline & & & & $\begin{array}{l}\text { Mild } \\
(\mathrm{N}=455)\end{array}$ & $\begin{array}{l}\text { Moderate } \\
(\mathrm{N}=480)\end{array}$ & $\begin{array}{l}\text { Severe or } \\
\text { very severe } \\
(N=158)\end{array}$ \\
\hline \multicolumn{7}{|l|}{ Demographic data } \\
\hline Mean (SD) age & $55.5(13.5)$ & $54.4(13.2)$ & $62.5(13.4)^{* * *}$ & $60.2(14.2)^{\mathrm{a}}$ & $63.0(13.0)^{a}$ & $67.2(10.8)^{b}$ \\
\hline$\%(\mathrm{~N})$ male & 46.4 (3808) & $44.7(3185)$ & $57.0(623)^{* * *}$ & $50.8(231)^{a}$ & $61.9(297)^{b}$ & $60.1(95)^{a, b}$ \\
\hline$\%$ (N) manual occupation & 44.6 (3664) & $43.6(3105)$ & $51.1(559)^{* \star \star}$ & $44.6(203)^{a}$ & $55.6(267)^{b}$ & $56.3(89)^{b}$ \\
\hline Mean (SD) deprivation score $†$ & $1.1(1.2)$ & $1.1(1.1)$ & $1.3(1.2)^{* \star *}$ & $1.2(1.2)^{\mathrm{a}}$ & $1.7(1.2)^{\mathrm{b}}$ & $1.8(1.2)^{b}$ \\
\hline \multicolumn{7}{|l|}{ Smoking characteristics } \\
\hline Age 36-44 & $30.4(654)$ & $29.6(599)$ & $43.3(55)^{\star *}$ & $45.5(35)^{a}$ & $40.0(18)^{a}$ & $40.0(2)^{a}$ \\
\hline Age $45-54$ & $28.8(610)$ & 26.7 (511) & $47.8(99)^{* \star *}$ & $37.5(39)^{a}$ & $57.3(51)^{\mathrm{b}}$ & $64.3(9)^{a, b}$ \\
\hline Age $55-64$ & $22.0(379)$ & $19.1(281)$ & $40.0(98)^{* \star \star}$ & $26.5(26)^{a}$ & $47.2(50)^{b}$ & $53.7(22)^{b}$ \\
\hline Age $65+$ & $15.1(335)$ & $12.0(205)$ & $25.3(130)^{\star \star *}$ & $19.3(34)^{\mathrm{a}}$ & $27.1(65)^{a, b}$ & $31.6(31)^{\mathrm{b}}$ \\
\hline \multicolumn{7}{|l|}{ All ages } \\
\hline Current & 24.1 (1978) & $22.4(1596)$ & $34.9(382)^{* * *}$ & $29.5(134)^{a}$ & $38.3(184)^{b}$ & $40.5(64)^{b}$ \\
\hline Ever & $55.1(4529)$ & $52.8(3758)$ & $70.5(771)^{* * *}$ & $60.4(275)^{a}$ & $75.8(364)^{b}$ & $83.5(132)^{b}$ \\
\hline Mean (SD) cigarettes/day $\ddagger$ & $15.1(9.5)$ & $14.8(9.2)$ & $16.3(10.4)^{*}$ & $16.3(9.2)^{a}$ & $17.1(11.6)^{\mathrm{a}}$ & $13.9(8.5)^{\mathrm{a}}$ \\
\hline Mean (SD) saliva cotinine $(\mathrm{ng} / \mathrm{ml}) \neq$ & $286(177)$ & 278 (177) & $322(173)^{* * *}$ & $306(171)^{a}$ & $336(169)^{a}$ & $318(192)^{a}$ \\
\hline Mean (SD) dependence rating & $3.7(1.0)$ & $3.6(1.0)$ & $3.9(1.0)^{* \star *}$ & $3.9(1.0)^{\mathrm{a}}$ & $3.8(0.9)^{\mathrm{a}}$ & $3.6(1.0)^{a}$ \\
\hline$\%(\mathrm{~N})$ motivated to quits & $68.9(1200)$ & $68.0(955)$ & $70.8(239)$ & $65.2(76)^{a}$ & $77.3(126)^{a}$ & $61.8(37)^{a}$ \\
\hline \multicolumn{7}{|l|}{ Respiratory diagnosis } \\
\hline$\%(N)$ chronic bronchitis/ & $1.1(89)$ & $0.7(52)$ & $3.4(37)^{\star * *}$ & $0.4(2)^{a}$ & $3.3(16)^{b}$ & $12.0(19)^{c}$ \\
\hline $\begin{array}{l}\text { emphysema } \\
\% \text { (N) asthma }\end{array}$ & $5.6(456)$ & $4.5(319)$ & $12.5(137)^{* \star *}$ & $5.1(23)^{a}$ & $14.0(67)^{b}$ & $29.7(47)^{c}$ \\
\hline$\%$ (N) undefined & $2.0(164)$ & 1.7 (123) & $3.8(41)^{* \star *}$ & $0.9(4)^{a}$ & $5.0(24)^{b}$ & $8.2(13)^{b}$ \\
\hline$\%$ (N) any & $8.2(671)$ & $6.5(466)$ & $18.8(205)^{\star \star *}$ & $6.4(29)^{a}$ & $21.3(102)^{b}$ & $46.8(74)^{c}$ \\
\hline \multicolumn{7}{|c|}{$\begin{array}{l}* * * p<0.001,{ }^{* *} p<0.01,{ }^{*} p<0.02 \\
\dagger \text { Adjusted for age. } \\
\text { fExcluding non-smokers. } \\
\text { - Adjusted for age, sex and deprivation level. } \\
\text { §Adjusted for age and sex. } \\
a, b, c \text { Different letters indicate significant group differences }(p<0.02) \text {. }\end{array}$} \\
\hline
\end{tabular}

underdiagnosis decreased significantly in relation to disease severity but, even among those with severe or very severe COPD, less than half reported a respiratory diagnosis (table 1).

\section{Demographic characteristics and smoking patterns of people with COPD}

People with spirometry-defined COPD were more likely to be older, manual workers, male, and socioeconomically deprived than those without the disease, and increasingly so in relation to disease severity (table 1 ). They were also more likely to be diagnosed with a respiratory disease of any kind than people without COPD. Similarly, the more severe the disease, the more likely people were to volunteer a diagnosis of chronic bronchitis/emphysema, asthma or any other respiratory disease.

A significantly larger proportion of people of all ages with spirometry-defined COPD reported having ever been a smoker than respondents without COPD (table 1). Current cigarette smoking was also significantly higher among people with COPD $(34.9 \%, 95 \%$ CI 32.1 to 37.8$)$ than among those without COPD $(22.4 \%, 95 \%$ CI 21.4 to 23.4$)$. The increased likelihood of current cigarette smoking for those with spirometry-defined COPD remained after adjustment for sex, age, ethnicity, and level of deprivation (odds ratio (OR) 2.31, CI 1.99 to 2.68). Smokers with COPD also exhibited higher levels of cigarette dependence, smoked more cigarettes a day, and had higher cotinine concentrations. However, they did not display higher motivation to quit than smokers without COPD; this effect remained after adjusting for age and sex differences.

As can be seen in table 1, there was a graded association between severity of lung function impairment and current cigarette smoking; greater impairment was associated with higher smoking prevalence even when controlling for age, sex, ethnicity, and deprivation level $(\beta=0.124, \mathrm{p}<0.001)$. While the majority of people with mild spirometry-defined COPD were former or never smokers $(70.5 \%)$, this proportion decreased to $59.5 \%$ in people with severe or very severe COPD. Differences in current smoking were significant between those with mild and those with moderate or severe/very severe COPD (table 1).

Self-reported smoking status was compared with cotinine validated smoking in order to estimate misreporting of current smoking in this sample. Among adults of all ages with spirometry-defined COPD, a significantly higher

Table 2 Prevalence of spirometry-defined COPD by smoking status

\begin{tabular}{lllll}
\hline COPD & $\begin{array}{l}\text { Total } \\
(\mathbf{N}=8215)\end{array}$ & $\begin{array}{l}\text { Never smokers } \\
(\mathbf{N}=3686)\end{array}$ & $\begin{array}{l}\text { Ex-smokers } \\
(\mathbf{N}=2551)\end{array}$ & $\begin{array}{l}\text { Smokers } \\
(\mathbf{N}=1978)\end{array}$ \\
\hline Mild & $5.5(455)$ & $4.9(180)^{a}$ & $5.5(141)^{a, b}$ & $6.8(134)^{b}$ \\
Moderate & $5.8(480)$ & $3.1(116)^{a}$ & $7.1(180)^{b}$ & $9.3(184)^{c}$ \\
Severe/very severe & $1.9(158)$ & $0.7(26)^{\mathrm{a}}$ & $2.7(68)^{\mathrm{b}}$ & $3.2(64)^{\mathrm{b}}$ \\
Overall & $13.3(1093)$ & $8.7(322)^{\mathrm{a}}$ & $15.2(389)^{\mathrm{b}}$ & $19.3(382)^{\mathrm{c}}$ \\
\hline
\end{tabular}

Data shown as \% (N).

$a, b, c$ Different letters indicate significant group differences $(p<0.02)$. 


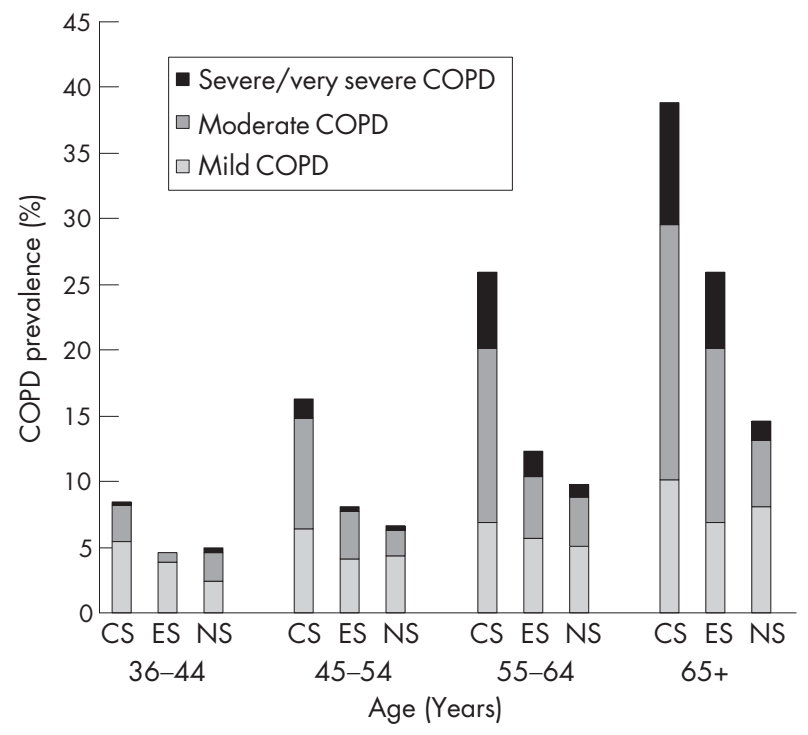

Figure 1 COPD status stratified by age and smoking status. CS, current smokers; ES, ex-smokers; NS, never smokers.

proportion of self-reported non-current smokers were actually smokers $(5.7 \%)$ than among people with normal lung function (3.3\%; OR $1.8,95 \%$ CI 1.2 to 2.6 ). The majority of misreporting was accounted for by smokers claiming to be ex-smokers rather than never smokers.

Figure 2 highlights changes in smoking cessation behaviour over time among people with and without COPD by looking at the quit ratio. The quit ratio represents the proportion of people who have given up smoking out of the total of people who reported having ever smoked regularly within each year group, and thus excludes the population of never smokers. There was a trend towards smoking cessation over time irrespective of COPD status; an increase in age was associated with an increase in the quit ratio. However, within each age group the quit ratio was considerably lower for people with than without COPD. As they grow older, smokers who already have spirometry-defined COPD were much more likely to continue smoking and much less likely to give up smoking than smokers without COPD.

\section{DISCUSSION}

To our knowledge, this study provides the first large scale estimate of spirometrically defined COPD in England and one of very few estimates using objective diagnostic measures in a nationally representative population sample from any country in the world. ${ }^{31}$ Our results are broadly comparable to previous COPD prevalence estimates employing spirometric testing, and higher prevalence figures reported in some ${ }^{9}$ but not other studies ${ }^{6}$ are probably due to differences in the age groups tested. This study also provides the first national estimate of the extent of underdiagnosis of this disease in England and indicates that, even with an inclusive definition of self-reported diagnosis, more than $80 \%$ of all cases did not report a clinical diagnosis and that, even in the severe or very severe category, only $50 \%$ appear to have been clinically diagnosed. As would be expected, while the majority of people with COPD were former or never smokers, the prevalence of current cigarette smoking in people with spirometry-defined COPD was higher than in the general population and this is the first study to provide an estimate of that prevalence. We found that almost half of those with spirometry-defined COPD smoked in middle age and that, across all ages, smokers with COPD were less likely to quit than those without impaired lung function. They also tended

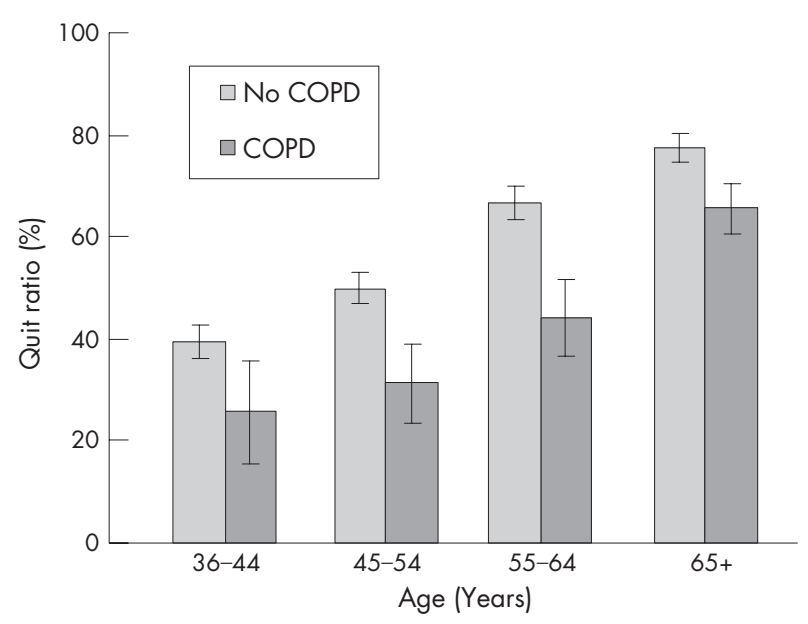

Figure 2 Quit ratio: ex-smokers as a proportion of ever smokers by age group and COPD status.

to be more cigarette dependent than those without COPD, but not more motivated to stop.

This study has a number of limitations. Firstly, the assessment of COPD was based on spirometry alone and did not involve reversibility testing to exclude asthma. Since the sample included participants below 45 years of age when asthma may be more probable than COPD, this may have resulted in an overestimation of COPD prevalence. However, there is considerable controversy regarding the use of reversibility testing to identify COPD as response to testing can be variable and therefore misleading. ${ }^{32}$ Moreover, the overlap between irreversible airway obstruction and chronic (obstructive) asthma is generally acknowledged, the latter being included in the ICD-10 definition of COPD. We therefore believe that the use of spirometric assessment alone to estimate COPD prevalence in a large sample above 35 years of age is justified. Secondly, as people who did not participate in spirometric testing differed in a number of demographic characteristics, this may have biased results leading to an underestimation of COPD prevalence. However, as our results were comparable to previous studies, this bias, if present, did not have a large effect on prevalence rates. Lastly, we had to rely on self-reports to determine whether a respiratory condition had been detected previously. While recall bias may have affected the reliability of reported conditions, this would have been counteracted by our liberal definition of "undiagnosed" COPD.

These results have implications for the recognition, prevention, and treatment of COPD in primary and secondary care. Increasing awareness of COPD in the general population and specifically among smokers would aid the early diagnosis of this disease. The high level of smoking among people with spirometry-defined COPD and unreliability of self-reported smoking status among smokers with COPD underlines the necessity of objective assessment of smoking status in chest clinics. In primary care there is a need to identify middle aged smokers with undiagnosed COPD. While many would be mild or moderate cases, these smokers would also experience the greatest personal health gain from quitting ${ }^{33}$ and are therefore a particularly strong priority group for intervention. ${ }^{34}$ Based on estimates of lung function decline in smokers and non-smokers, ${ }^{35}$ one in every three current smokers with mild or moderate COPD in this sample who would go on to develop severe or very severe COPD over the next 5 years could avoid this disease progression if they stopped smoking.

The societal economic burden of COPD far outweighs the cost of routine spirometric assessment of at-risk smokers in 
primary care. ${ }^{16}{ }^{17}{ }^{36}$ However, a diagnosis with a respiratory disease is not enough; ${ }^{37}$ high levels of nicotine dependence among people with COPD militate against the effectiveness of spirometry feedback and brief smoking counselling alone. Interventions aimed at middle aged smokers with COPD need to be more intensive in order to increase their desire to stop and address the greater level of addiction in this group. As has been shown by the Lung Health Study, ${ }^{21} 22$ aggressive and prolonged smoking cessation treatment can make a real difference in terms of lung function decline and mortality from COPD. Although it is unlikely that the duration and intensity of support that was given in the Lung Health Study would be offered to smokers more generally, the imperative to achieve cessation as soon as possible is so great in this group that arguably they may be considered a special case.

\section{ACKNOWLEDGEMENT}

The authors thank David Boniface and Martin Shipley for statistical advice.

\section{Authors' affiliations}

L Shahab, M J Jarvis, R West, Cancer Research Health Behaviour Unit, Department of Epidemiology and Public Health, University College London, London WCIE 6BT, UK

$\mathrm{J}$ Britton, Division of Epidemiology and Public Health, University of Nottingham, Clinical Sciences Building, City Hospital, Nottingham NG5 IPB, UK

Funding: LS is an MRC funded PhD student. RW is funded by Cancer Research UK and MRC.

Competing interests: MJJ has accepted honoraria for speaking and travelling expenses from pharmaceutical companies making smoking cessation products. JB and RW have undertaken research and consultancy for companies developing and manufacturing smoking cessation medications. RW is also a co-holder of a patent for a novel nicotine inhalation device.

The Health Survey for England is commissioned by the Department of Health and carried out by the Joint Survey Unit of the National Centre for Social Research and the Department of Epidemiology and Public Health, University College London. The data were made available through the UK Data Archive. These bodies bear no responsibility for the analyses and interpretation reported here.

\section{REFERENCES}

1 Murray CJ, Lopez AD. Alternative projections of mortality and disability by cause 1990-2020: Global Burden of Disease Study. Lancet 1997;349:1498-504.

2 National Collaborating Centre for Chronic Conditions. Chronic obstructive pulmonary disease. National clinical guideline on management of chronic obstructive pulmonary disease in adults in primary and secondary care. Thorax 2004;59(Suppl 1): 1-232.

3 Office for National Statistics. Mortality statistics by cause, Series DH2 No.30. London: The Stationery Office, 2004

4 Renwick DS, Connolly MJ. Prevalence and treatment of chronic airways obstruction in adults over the age of 45. Thorax 1996;51:164-8.

5 Dickinson JA, Meaker M, Searle M, et al. Screening older patients for obstructive airways disease in a semi-rural practice. Thorax 1999:54:501-5.

6 Mannino DM, Gagnon RC, Petty TL, et al. Obstructive lung disease and low lung function in adults in the United States: data from the National Health and Nutrition Examination Survey, 1988-1994. Arch Intern Med 2000;160:1683-9.

7 Pena VS, Miravitlles M, Gabriel R, et al. Geographic variations in prevalence and underdiagnosis of COPD: results of the IBERPOC multicentre epidemiological study. Chest 2000;118:981-9.

8 Huchon GJ, Vergnenegre A, Neukirch F, et al. Chronic bronchitis among French adults: high prevalence and underdiagnosis. Eur Respir J 2002;20:806-12.
9 Kim DS, Kim YS, Jung KS, et al. Prevalence of chronic obstructive pulmonary disease in Korea: a population-based spirometry survey. Am J Respir Crit Care Med 2005;172:842-7.

10 Doll R, Peto R, Wheatley $K$, et al. Mortality in relation to smoking: 40 years' observations on male British doctors. BMJ 1994;309:901-11.

11 Doll R. Risk from tobacco and potentials for health gain. Int J Tuberc Lung Dis 1999;3:90-9.

12 Fletcher $\mathrm{C}$, Peto $\mathrm{R}$, Tinker $\mathrm{C}$, et al. The natural history of chronic obstructive bronchitis and emphysema: an 8-year study of early chronic obstructive lung disease in working men in London. New York: Oxford University Press, 1976.

13 Lange P, Groth S, Nyboe GJ, et al. Effects of smoking and changes in smoking habits on the decline of $\mathrm{FEV}_{1}$. Eur Respir J 1989:2:811-6.

14 Kornmann O, Beeh KM, Beier J, et al. Newly diagnosed chronic obstructive pulmonary disease. Clinical features and distribution of the novel stages of the Global Initiative for Obstructive Lung Disease. Respiration 2003;70:67-75.

15 Lundback B, Lindberg A, Lindstrom $M$, et al. Not 15 but $50 \%$ of smokers develop COPD? Report from the Obstructive Lung Disease in Northern Sweden studies. Respir Med 2003;97:115-22.

16 Calverley P, Bellamy D. The challenge of providing better care for patients with chronic obstructive pulmonary disease: the poor relation of airways obstruction? Thorax 2000:55:78-82.

17 van Schayck CP, Chavannes NH. Detection of asthma and chronic obstructive pulmonary disease in primary care. Eur Respir J Suppl 2003;39:16-22s.

18 Floreani AA, Rennard SI. The role of cigarette smoke in the pathogenesis of asthma and as a trigger for acute symptoms. Curr Opin Pulm Med 1999;5:38-46.

19 Wise RA, Kanner RE, Lindgren P, et al. The effect of smoking intervention and an inhaled bronchodilator on airways reactivity in COPD: the Lung Health Study. Chest 2003;124:449-58.

20 van der Meer RM, Wagena EJ, Ostelo RW, et al. Smoking cessation for chronic obstructive pulmonary disease. Cochrane Database Syst Rev 2003;(2):CD002999.

21 Kanner RE, Connett JE, Williams DE, et al. Effects of randomized assignment to a smoking cessation intervention and changes in smoking habits on respiratory symptoms in smokers with early chronic obstructive pulmonary disease: the Lung Health Study. Am J Med 1999;106:410-6.

22 Anthonisen NR, Connett JE, Murray RP. Smoking and lung function of Lung Health Study participants after 11 years. Am J Respir Crit Care Med 2002; 166:675-9

23 Prior G, Deverill C, Malbut K, et al. Health Survey for England 2001: Methodology and Documentation. London: The Stationery Office, 2003.

24 Jarvis MJ, Wardle J, Waller J, et al. Prevalence of hardcore smoking in England, and associated attitudes and beliefs: cross sectional study. BMJ 2003;326:1061.

25 Feyerabend C, Russell MA. A rapid gas-liquid chromatographic method for the determination of cotinine and nicotine in biological fluids. J Pharm Pharmacol 1990;42:450-2

26 Jarvis MJ, Tunstall-Pedoe $\mathrm{H}$, Feyerabend $\mathrm{C}$, et al. Comparison of tests used to distinguish smokers from nonsmokers. Am J Public Health 1987;77:1435-8.

27 Celli BR, MacNee W. Standards for the diagnosis and treatment of patients with COPD: a summary of the ATS/ERS position paper. Eur Respir $J$ 2004;23:932-46

28 Quanjer PH, Tammeling GJ, Cotes JE, et al. Lung volumes and forced ventilatory flows. Report Working Party Standardization of Lung Function Tests, European Community for Steel and Coal. Official Statement of the European Respiratory Society. Eur Respir J Suppl 1993;16:5-40.

29 Heatherton TF, Kozlowski LT, Frecker RC et al. Measuring the heaviness of smoking: using self-reported time to the first cigarette of the day and number of cigarettes smoked per day. Br J Addict 1989;84:791-9.

30 Doherty DE, Briggs DD Jr. Chronic obstructive pulmonary disease: epidemiology, pathogenesis, disease course, and prognosis. Clin Cornerstone 2004; (Suppl 2):S5-16.

31 Halbert RJ, Isonaka S, George D, et al. Interpreting COPD prevalence estimates: what is the true burden of disease? Chest 2003;123:1684-92.

32 Calverley PM, Burge PS, Spencer S, et al. Bronchodilator reversibility testing in chronic obstructive pulmonary disease. Thorax 2003:58:659-64.

33 Pride NB. Smoking cessation: effects on symptoms, spirometry and future trends in COPD. Thorax 2001;56(Suppl II):ii7-10.

34 Wilson D, Adams R, Appleton S, et al. Difficulties identifying and targeting COPD and population-attributable risk of smoking for COPD: a population study. Chest 2005;128:2035-42.

35 James AL, Palmer $\sqcup$, Kicic E, et al. Decline in lung function in the Busselton Health Study: the effects of asthma and cigarette smoking. Am J Respir Crit Care Med 2005;171:109-14.

36 Britton $M$. The burden of COPD in the UK: results from the Confronting COPD survey. Respir Med 2003;97(Suppl C):S71-9.

37 Badgett RG, Tanaka DJ. Is screening for chronic obstructive pulmonary disease justified? Prev Med 1997;26:466-72. 